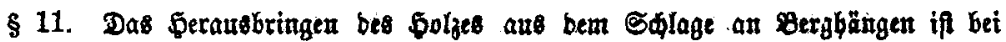
(S)atteis ju unterjagen.

\$ 12. Dnb Befteigen non fegenben Bäumen mittels Steigeifen bebuf Entäftung Dber Sewintung yon Samenzapfen bei Slatteis an ber Minbe ber Bärme if zu unterjagen.

813. Seber भrbetter, welder einen ftebenben Baum mittels Steigeijen befteigt, bat fid fiet8 eines Sidjerbetitofeile zu bebienen.

Das überfpringen son einem Banmgipfel auf ben anbern if unterjagt.

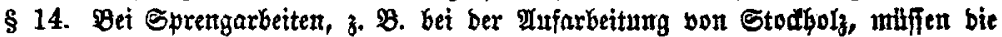

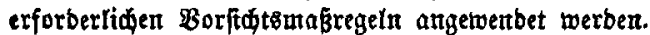

\$15. Bei ftarfem Froftwetter finb bie zutm Spalten bes \$olzes zu benułenben

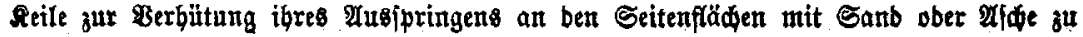
befirenen.

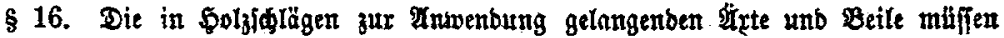
gut berfeilt fein unt bie 5elme biurfen leine fobbhaften Stellen entbalten.

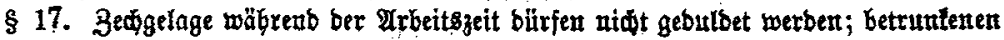
Mrbeitern barf bas Mrbeiten ni申t geftattet merben.

Sebem Dolghauter if ein Eremplar biefer Beftimmungen eingebänbigt unb finb bie Forft utto Oberforftereien beauftrngt tworben, bas Forftidusperjonal utb bie Solghauer eingebenb zis inftruteren, fowie bie Befolgung ber erteilten Borfdriften ftreng zu taber: twadien.

H.

\title{
V. Amzeigen.
}

3eiteinteflung für die am 30. Zluguft bis 2. September 1892 in Stutts gart tagende Derfammlung deut\}ḩer forftmärner.

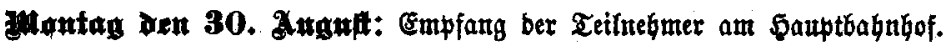
Abenb gefellige Bereinigung.

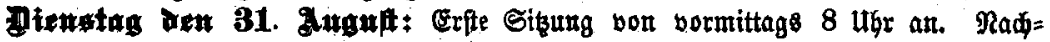
mittag8 Exturfion in bas forftrebier Sobenbeim.

I benb gefelfige Bereinigung.

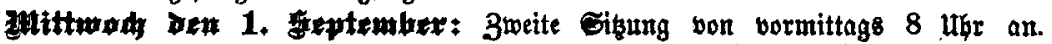
Rađmittags Befidtigung ber Sebenswürbigfeiten bon Stuttgart unb Jeftefen.

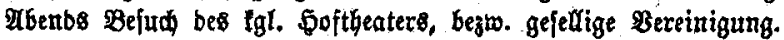

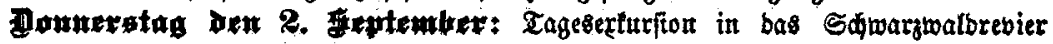
Freubenftabt. ફ̧in= unb Rüdfaht ntit Sonberzug.

Beplant if eine Mađerturfton am 3. September in ben Mlbforfibegirl urađ.

Das befinitibe Programm mirb in täbften \$eft belant gegeben werben.

Stuttgart, im Mai 1897.

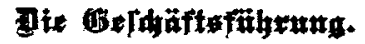

\section{Berifitigung.}

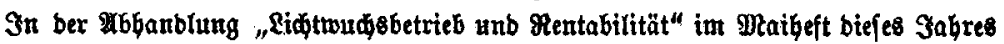

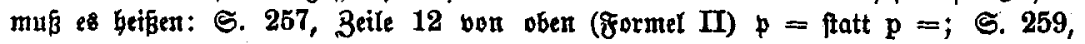
Beile 9 von unten $\frac{5400}{0,08}+11000 \mu$ ftatt $\frac{5400}{0,03}+\mathrm{c}=11000 \mu$. 